\title{
CAPM Condicional no Mercado Brasileiro: Um Estudo dos Efeitos Momento, Tamanho e Book-to-Market entre 1995 e 2008
}

\author{
Frederico Valle e Flister* \\ Aureliano Angel Bressan** \\ Hudson Fernandes Amaral***
}

\begin{abstract}
Resumo
Este artigo procurou verificar se o modelo CAPM condicional é capaz de explicar anomalias de momento, tamanho e book-to-market, utilizando metodologia proposta por Lewellen \& Nagel (2006) no mercado acionário brasileiro. Para tal, foi estudada uma amostra de ações negociadas na Bovespa no período de julho de 1995 a junho de 2008, em uma base mensal. Os resultados indicam que somente a anomalia book-to-market foi significativa estatisticamente. O modelo condicional, testado a partir de séries temporais de 12 meses, também não apresentou ganhos significativos em relação à forma não-condicional. Todavia, foi observado que os betas variam no tempo, sugerindo que o tamanho da série temporal no cálculo dos betas pode influenciar na escolha de carteiras, ou seja, a evidência de variação dos betas no tempo significa que análises baseadas no CAPM devem ser cautelosas ao utilizarem modelos incondicionais.
\end{abstract}

Palavras-chave: CAPM condicional; book-to-market; tamanho; momento.

Código JEL: G12.

\section{Abstract}

This paper investigates the ability of the conditional CAPM to explain anomalous returns related to momentum, size and book-to-market effects using Lewellen and Nagel's(2006) methodology in the Brazilian stock market. To this end we studied a sample of Bovespa's stocks in a monthly basis from July 1995 to June 2008. The results indicate that only the book-to-market effect presents statistical significance. The conditional model, tested from time series of 12 months, also showed no significant gains in relation to the unconditional form. However, there are evidences that betas do vary over time, suggesting that the sample size on beta calculations may influence portfolio choices, i.e., the evidence of variation in betas over time means that analysis based on the CAPM should be cautious when using unconditional models.

Keywords: conditional CAPM; book-to-market; size; momentum.

Submetido em abril de 2010. Aceito em setembro de 2010. O artigo foi avaliado segundo o processo de duplo anonimato além de ser avaliado pelo editor. Editor responsável: Newton Costa Jr.

*CEPEAD-UFMG, Minas Gerais, Brasil. E-mail: fredericoflister@gmail.com

**CEPEAD-UFMG, Minas Gerais, Brasil. E-mail: aureliano.bressan@gmail.com

***CEPEAD-UFMG, Minas Gerais, Brasil. E-mail: hfamaral@face.ufmg.br 


\section{Introdução}

O modelo de Precificação de Ativos de Capital, ou Capital Asset Pricing Model (CAPM) desde a sua introdução por Sharpe (1964), Lintner (1965) e Mossin (1966), tem recebido bastante atenção do mundo acadêmico e do mundo financeiro pela sua importância para a avaliação de ativos de risco e para sua expectativa de retorno. Não obstante, o modelo passou também a receber várias críticas, sendo uma das mais contundentes a de Roll (1977), que argumenta que o CAPM não pode ser empiricamente testado, por ser praticamente impossível estimar a carteira de mercado.

Outros trabalhos, tanto nos Estados Unidos como no Brasil, ${ }^{1}$ também apontam que a precificação auferida por este modelo não consegue explicar o retorno de todas as carteiras. O pressuposto de que as informações passadas estavam contidas nos retornos das ações foi questionado quando carteiras construídas para caracterizar as anomalias "momento" (retornos passados), "tamanho" e "book-to-market" apresentaram retorno superior à expectativa gerada pelo CAPM.

A esse respeito, Jagannathan \& Wang (1996) contra-argumentam que os trabalhos que atestaram anomalias no CAPM somente o consideraram na sua forma estática. Ou seja, estes desconsideraram o fato de que as variâncias e covariâncias dos ativos se alteram com o passar do tempo. Em função disto, estes autores utilizaram o CAPM na sua forma condicional, permitindo que alterações nas variâncias e covariâncias dos ativos fossem consideradas para tentar explicar as anomalias supracitadas. Os autores obtiveram explicação estatística mais significante do que na versão não-condicional do modelo CAPM aplicado ao mercado norteamericano no período de 1962 a 1990.

Outros trabalhos seguiram a mesma linha, tais como o estudo de Lettau \& Ludvigson (2001), nos EUA, e de Tambosi (2003) e Tambosi et al. (2010), que analisaram os mercados acionários no Chile, Brasil e Argentina. No estudo mais recente, os resultados são condizentes com as conclusões do estudo de Jagannathan \& Wang (1996) para o mercado norte-americano.

No entanto, Cochrane (2005) aponta que o uso de variáveis proxy de informação para a estimação do CAPM condicional não seria capaz de captar toda variação nos coeficientes deste modelo, por não responder por toda informação disponível aos investidores. Nesta perspectiva, Lewellen \& Nagel (2006) propõem então uma nova metodologia para o teste da explicação de anomalias do CAPM estático pelo CAPM condicional, com base em séries temporais que não necessitam do uso de uma proxy para informação condicional. Os autores concluíram que o CAPM na sua forma condicional não apresentou ganho significativo na explicação das carteiras baseadas na anomalias tamanho, book-to-market e momento em relação à forma estática. Segundo estes autores, a alteração na variância dos betas e sua co-

\footnotetext{
${ }^{1}$ Alguns exemplos no Brasil: Costa \& O'hanlon (2000), Ramos et al. (2000), Ribenboim (2002), Bonomo \& Dall'agnol (2003), Minardi (2004) e Mussa et al. (2007).

${ }^{2} \mathrm{~A}$ relação book-to-market é expressa pela razão entre o valor contábil das ações pelo seu valor de mercado.
} 
variância com a carteira de mercado deveriam ser muito maiores do que os valores verificados nos EUA para que o CAPM condicional conseguisse explicar essas anomalias.

É dentro desta abordagem que o presente artigo é desenvolvido, com o objetivo de aplicar a proposta de Lewellen \& Nagel (2006) no Brasil, buscando maiores informações sobre a aplicabilidade do CAPM na sua forma condicional e como ele se comporta com carteiras de tamanho, book-to-market e momento no mercado acionário brasileiro no período de 1995 a 2008.

Na próxima seção será apresentada uma breve revisão sobre as anomalias de tamanho, momento e book-to-market no Brasil, bem como de estudos do CAPM Condicional no Brasil e no exterior. Nas duas seções seguintes, serão apresentados o referencial teórico e a metodologia utilizada. A quinta e a sexta seções apresentam os resultados e as conclusões do estudo.

\section{Literatura Recente}

\section{Efeitos momento, book-to-market e tamanho no mercado brasileiro}

Mescolin et al. (1997) estudaram o mercado brasileiro no período de junho de 1989 a junho de 1996 e encontram um retorno superior da carteira de ações de valor (value stocks) em relação às as ações de crescimento (growth stocks), sendo que o risco calculado pelo coeficiente beta do CAPM não apresenta diferença significativa entre as carteiras.

Já o estudo de Bruni (1998) não encontra relação significativa entre o beta e os retornos de ações na Bovespa no período de 1988 a 1996. O autor encontrou forte relação entre a informação book-to-market das empresas e os retornos das suas ações. Os indicadores "ativos totais/valor de mercado" como proxy de endividamento e "preço/vendas" também mostraram relação significativa com o retorno dos ativos. Para a variável "tamanho" foi encontrada uma relação positiva com os retornos dos ativos apenas no período de 1995 a 1996, indicando que ações de empresas maiores apresentam retornos maiores do que empresas menores, contradizendo a evidência encontrada no mercado norte-americano por Fama \& French (1992).

Ramos et al. (2000) utilizando abordagem similar à de Fama \& French (1992) na relação book-to-market, realizaram um estudo para o período de 1988 a 1994 na Bovespa, no qual descobriram que growth stocks renderam menos que as value stocks, mas tiveram um nível de risco um pouco menor. Os autores utilizaram apenas uma carteira para growth stocks e outra para value stocks, cada uma contendo um quintil das ações negociadas na Bovespa para o período analisado conforme a classificação book-to-market adotada. Apesar de admitirem uma oportunidade de ganho no longo prazo, os autores sugerem cautela na interpretação dos resultados, dada a baixa significância estatística quando se testa a hipótese de que a carteira com maior retorno tem risco inferior ao da carteira de menor retorno. 
Costa \& O'hanlon (2000) encontraram uma falha no CAPM para explicar carteiras que levam em conta o efeito tamanho no mercado brasileiro no período de 1970 a 1989. Já Bonomo \& Dall'agnol (2003) encontraram evidências de que ações com menor tamanho apresentam maior retorno que ações de maior tamanho, não explicado pelo CAPM, entre 1986 e 2000, na Bovespa.

Minardi (2004) procurou testar a correlação dos retornos passados com os futuros no período de setembro de 1994 a dezembro de 2000 no mercado de ações brasileiro. Utilizando informações de retorno de 649 ativos, a autora calculou, a partir de séries defasadas de doze meses, regressões cross section para estimar o retorno do mês seguinte. Foram estimadas 58 regressões para cada um dos meses entre o período de outubro de 1995 e julho de 2000, eliminando as ações que não continham dados contínuos dos últimos doze meses. A análise envolveu a montagem de dez carteiras formadas por meio do agrupamento de ativos pela ordem decrescente de retorno estimado para cada uma das 649 ações nas regressões. Os resultados obtidos mostraram que a carteira com maior retorno previsto obteve melhor desempenho que as carteiras com menor retorno previsto, além de ter apresentado resultado econômico superior ao de mercado. No entanto, a autora concluiu que o ganho não compensaria os custos de corretagem ao aplicar tal estratégia.

Oliveira \& Carrete (2005) realizaram um estudo da anomalia book-to-market na Bovespa, avaliando a previsibilidade de ações do tipo growth sobre o prêmio de risco do CAPM. Com uma amostra que abrange o período de janeiro de 1995 a agosto de 2004, encontraram uma relação negativa e estatisticamente relevante do retorno dos trinta e seis meses passados da carteira tipo growth e o prêmio de mercado medido pela diferença de retorno entre o Ibovespa e a taxa do CDI, apontando para a evidência de haver comportamento irracional, isto é, de que os investidores tendem a avaliar como menos arriscadas ações com retorno passado positivo. Complementarmente, os autores verificaram que de 1998 a 2003 a carteira com menor índice book-to-market teve um retorno acumulado maior do que a carteira com maior índice book-to-market. Rostagno et al. (2006) aprofundaram o estudo da relação book-to-market para o mercado brasileiro, usando uma amostra de dezembro de 1994 até abril de 2003. Para definir as carteiras de growth stocks e value stocks, utilizaram além da relação do preço de mercado de uma ação pelo seu valor patrimonial, carteiras formadas por índices de lucro/preço; dividendos/preço, vendas/preço, ebitda/preço e tamanho. Utilizando o CAPM, os autores encontraram tanto para estratégia de book-to-market como para estratégias formadas pelos outros índices estudados, resultados estatisticamente significantes, que atestam que os retornos não poderiam ser explicados pelo CAPM, com exceção da estratégia que utilizava o índice dividendos/preço. Os autores também utilizaram sete medidas de risco para avaliar se os retornos anormais acarretam riscos maiores ou não para as carteiras com maior retorno. Com base na análise dos fatores de risco, a estratégia baseada em lucro/preço apresentou melhor retorno e melhores indicadores de risco, com exceção da liquidez, em relação às 
carteiras de menor retorno.

A relação entre book-to-market e variáveis contábeis associadas a empresas brasileiras negociadas na Bovespa foi estudada por Cupertino \& Coelho (2006). Segundo os autores, a razão book-to-market está relacionada com estratégias de investimento relacionadas com a alavancagem financeira e a relação do ativo imobilizado com bens intangíveis. Além disso, os autores verificaram que para uma amostra de empresas brasileiras entre 1995 a 2003 o valor contábil supera o valor de mercado na maioria das empresas. Com base nos resultados obtidos, foi observada apenas uma correlação fraca entre book-to-market e alavancagem financeira, expressada pela razão passivo exigível/ativo. Outras correlações foram rejeitadas para os anos de 1998, 2001 e 2004 com variáveis que indicavam liquidez, tamanho (a valor contábil), imobilizado e intangíveis. Foi também rejeitada a correlação entre o book-to-market e o beta calculado na amostra estudada.

Souza (2006) buscou encontrar estratégias de alocação entre a taxa do CDI e a carteira Ibovespa no período de janeiro de 1994 a agosto de 2005. Apoiando-se na literatura sobre anomalias do CAPM, o autor testou as variáveis independentes: book-to-market, preço-lucro, dividendo-preço e média de retorno no(s) último(s) $1,12,36$ e 60 meses em relação à variável dependente "retorno futuro" em horizontes de 1, 12, 36 e 60 meses. Em regressões univariadas para cada variável independente, somente a razão book-to-market, e a média de retorno passado de 60 meses anteriores foram estatisticamente relevantes quando utilizado um retorno futuro de 60 meses, sendo que a regressão que utilizou a razão book-to-market apresentou R-quadrado de $75,1 \%$. O modelo multivariado foi estimado com as variáveis book-to-market, preço-lucro e dividendo-preço, sendo que a média de retorno dos últimos 60 meses foi excluída por apresentar dependência linear com as outras variáveis. Os resultados mostram que todas as variáveis são relevantes em um horizonte de 60 meses. A partir deste modelo multivariado, Souza (2006) foi capaz de utilizar estratégias que em um horizonte de 60 meses apresentaram ganho de retorno por unidade de risco acima da média de mercado.

Mussa et al. (2007) utilizaram a mesma metodologia de Jegadeesh \& Titman (1993), de comprar ganhadores e vender perdedores para o mercado de ações da Bolsa de Valores de São Paulo (Bovespa) no período de 1995 a 2006. Das dezesseis estratégias analisadas o maior retorno anormal mensal, de $1,4 \%$, foi da estratégia que classifica as ações conforme os retornos dos últimos três meses e as mantêm por seis meses $(3 \times 6)$. Outras duas estratégias que tiveram retorno positivo foram a de $6 \times 9$ e a de $9 \times 9$. Apesar de o retorno mensal encontrado ter sido maior que o verificado por Jegadeesh e Titman (1993) nos Estados Unidos, os autores concluíram que a evidência no Brasil é mais fraca, pois somente 3 de 16 estratégias testadas apresentaram retorno positivo estatisticamente significativo.

Em um estudo posterior, Mussa et al. (2008) avaliaram o retorno das estratégias book-to-market, tamanho e momento em relação a períodos de expansão (ou retração) monetária e de expansão (retração) do índice Ibovespa. Para o período estudado, de junho de 1995 a junho de 2007, somente o retorno da estratégia book- 
to-market teve resultado estatisticamente diferente de zero. Quando a amostra é controlada para o período de baixa do mercado acionário, somente a estratégia tamanho é estatisticamente diferente de zero e positiva. No período de alta, as estratégias book-to-market e tamanho foram estatisticamente diferentes de zero, sendo que o retorno da estratégia tamanho passa a ser negativo. Quando as amostras são controladas pela política monetária feita pelo governo no momento, se contracionista ou expansionista, somente a estratégia de book-to-market é estatisticamente significante no período de restrição monetária. No período de expansão, nenhuma estratégia é estatisticamente significante. Os autores concluíram que a estratégia tamanho está relacionada com as condições de mercado, corroborando resultados de pesquisas em outros países. Já a estratégia book-to-market, cujos retornos são maiores quando a condição do mercado é de alta, está em consonância com a conclusão de Fama e French (1992) de que este índice pode estar associado a um prêmio de risco adicional.

\section{Estudos do CAPM condicional}

Jagannathan \& Wang (1996) testaram o modelo CAPM condicional para carteiras formadas a partir de estratégias de tamanho e book-to-market similares à abordagem de Fama \& French (1992). Estes autores utilizaram como proxy para o conjunto de informações disponíveis aos investidores o spread na taxa de juros entre títulos com baixa e alta classificação de risco. Das cem carteiras analisadas, o CAPM condicional explicou 30\% das variações na amostra em seção cruzada. Quando ponderados pelo retorno de capital humano, ${ }^{3}$ a explicação do modelo condicional passou a $50 \%$ das variações. Considerando que o modelo incondicional não explica $1 \%$ da variação e que os efeitos tamanho e book-to-market não ajudam a explicar o que faltou ser identificado pelo modelo, os autores acreditam ter encontrado suporte relevante ao CAPM condicional. No entanto, eles reconhecem que o modelo testado está mais próximo de um modelo multifatorial que de uma especificação do modelo condicional e que, em função disso podem não ter captado completamente a dinâmica do mercado implícita no modelo condicional.

Lewellen \& Nagel (2006) argumentam que a covariância entre os betas condicionais e o prêmio de mercado deve ser muito maior do que a sua melhor estimativa, que seria o produto do desvio padrão destas duas variáveis na hipótese de que a correlação entre os dois fosse perfeita para que o modelo condicional conseguisse explicar as anomalias de tamanho, book-to-market e momento. Utilizando uma metodologia que abrange o uso de séries temporais a cada 3, 6, 9 e 12 meses, evitando assim o uso de uma proxy para informações disponíveis, os autores conseguiram uma estimativa para uma série de betas condicionais que permitiu calcular a sua covariância com o retorno de mercado. Calculando ainda o alfa de Jensen para carteiras com efeitos de tamanho, book-to-market e momento, os autores concluíram que o CAPM na forma condicional, assim como na forma

\footnotetext{
${ }^{3} \mathrm{O}$ retorno de capital humano foi aproximado, no estudo, pela proxy crescimento per capita da renda do trabalho.
} 
incondicional, pouco contribui para a explicação dessas anomalias. Os autores estendem a sua conclusão para o CAPM de consumo, uma vez que a variação do crescimento do consumo é muito pequena para ajudar na explicação dessas anomalias. Ao considerar séries temporais de curta duração, Lewellen \& Nagel (2006) consideram o uso de variáveis proxy para o efeito condicional no CAPM desnecessário, tendo em vista que a maioria dos trabalhos que usam este tipo de variável escolhe séries de dados com pouca ou nenhuma variação no curto prazo como, por exemplo, o spread entre taxas de curto e longo prazo.

Utilizando a metodologia de Jagannathan \& Wang (1996), Tambosi (2003) procurou analisar o CAPM condicional para os mercados acionários do Brasil, Chile e Argentina. Para tal, utilizou uma quantidade menor de carteiras do que aquela utilizada no trabalho para o mercado norte-americano, sendo sete carteiras para o Brasil e cinco carteiras para Chile e Argentina, no período de 1994 a 2002. Utilizando como proxy de informação disponível o spread entre a taxa básica de juros de cada país e a taxa praticada pelo setor privado, ${ }^{4}$ encontrou relevância para essa variável para os três países, porém o poder explicativo do modelo para os retornos em seção cruzada pouco se alterou, sendo estes mais bem explicados pelo efeito tamanho. No estudo, resultados similares àqueles encontrados para o mercado norte-americano em Jagannathan \& Wang (1996) foram somente observados no mercado acionário Argentino.

Ribenboim (2002) testou o CAPM nas formas incondicional e condicional no mercado brasileiro empregando técnicas de máxima verossimilhança (MV) e método de momento generalizado (MMG) no período de junho de 1989 a março de 1998. Foram testadas carteiras formadas a partir do setor em que pertenciam os ativos, formando no total 14 carteiras. Os resultados apontam para a aceitação do CAPM incondicional no teste de MV e com certo viés para MMG. Para o CAPM condicional, os resultados indicam validade do modelo somente para as ações com maior liquidez no mercado. Adicionalmente, os resultados obtidos sinalizam para a importância da utilização do Ibovespa como proxy de mercado, dado que este índice contempla grande parte do volume transacionado do mercado acionário brasileiro.

Já Bonomo \& Garcia (2002) testaram o modelo CAPM condicional utilizando uma técnica para identificar processos autorregressivos do tipo ARCH. Para tal, utilizaram 25 ativos que fizeram parte do Ibovespa entre 1976 e 1992 e separaram em três carteiras de acordo com critério tamanho. Os resultados indicaram que há relação crescente dos retornos médios com o tamanho, e relação decrescente com a volatilidade dos retornos. Apesar de o CAPM condicional também não explicar a anomalia tamanho, o mesmo mostrou melhor ajuste aos dados do que o CAPM incondicional.

${ }^{4}$ Para o Brasil, Tambosi (2003) escolheu mais especificamente o spread entre a taxa de operações de depósitos interfinanceiros (DI), divulgadas pela Central de Custódia e Liquidação de Títulos Privados (CETIP) e a taxa referencial do Sistema Especial de Liquidação e de Custódia (Selic) para títulos federais. 
Antunes et al. (2006) testaram a anomalia tamanho na Bovespa no período de 1998 a 2004. Para o teste do efeito tamanho os autores utilizaram três proxies: valor de mercado, valor patrimonial e lucro. Os ativos ordenados foram então divididos em carteiras, as quais foram divididas em cinco quintis do total de ativos estudados. As equações do CAPM das carteiras apresentaram heterocedasticidade, que foi tratada pelos autores com o uso de um modelo GARCH-M. O uso do modelo GARCH-M na estimação da equação do CAPM implica, em verdade, numa forma de se estimar o modelo CAPM condicional. Utilizando essa metodologia foram encontrados resultados estatisticamente insignificantes para o retorno anormal da estratégia tamanho.

Mais recentemente, o estudo de Tambosi et al. (2010) aplica o modelo condicional de Jagannathan \& Wang (1996), incorporando variáveis macroeconômicas e financeiras para os mercados brasileiro, argentino e chileno, visando à comparação com o mercado norte americano. Os autores utilizam no modelo CAPM condicional, para cada um dos mercados analisados, os índices das respectivas bolsa de valores (Ibovespa, MERVAL e IPSE), spread entre taxas de juros domésticas (como proxy para as variações dos ciclos de negócios) e PIB (como proxy de capital humano). Os resultados obtidos, para uma amostra envolvendo o período entre jan/94 e dez/02, indicam que o CAPM estático, sem a inclusão da variável capital humano, não explica as variações cross-section nos mercados analisados e, diferentemente dos mercados norte-americano e argentino, os mercados brasileiro e chileno apresentam relação positiva entre os retornos médios das carteiras e o tamanho, com a carteira de maior tamanho apresentando retornos superiores. Os resultados indicam ainda que o CAPM condicional de Jagannathan \& Wang (1996) inicialmente proposto para o mercado norte-americano é aplicável aos mercados brasileiro, argentino e chileno utilizando as proxies do estudo.

\section{Modelo CAPM Condicional}

Mayers (1972) pode ser considerado o precursor de modelos de equilíbrio condicionais, ao desenvolver um modelo teórico de precificação que incorpora a existência de ativos não transacionáveis na carteira de mercado. Na abordagem moderna de modelos condicionais, apresentada em Jagannathan \& Wang (1996), considera-se que a economia é dinâmica e tem vários ciclos de negócio, o que é compatível com a idéia de que os investidores estão sempre revendo as suas expectativas conforme os retornos dos ativos variam no tempo (Jagannathan \& Wang, 1996).

Pressupondo então a presença de vários ciclos de negócios, considera-se que os betas dos ativos irão variar de acordo com a informação disponível em cada momento determinado no tempo. Adicionalmente, como destacado por Ribenboim (2002, p.26): “O CAPM condicional é uma forma conveniente para incorporar variâncias e covariâncias que se modificam ao longo do tempo". A fórmula do modelo condicional é representada da seguinte maneira: 


$$
E\left[r_{i t} \mid I_{t-1}\right]=r_{f}+\beta_{i, t-1}\left(E\left[r_{m t} \mid I_{t-1}\right]-r_{f}\right)
$$

em que $\beta_{i, t-1}=\operatorname{cov}\left(r_{i t}, r_{m t} \mid I_{t-1}\right) / \operatorname{var}\left(r_{m t} \mid I_{t-1}\right)$.

Assim, o que diferencia a forma condicional da forma estática é o conjunto de informações $\mathrm{I}_{t-1}$, que representa as informações disponíveis para os investidores no período imediatamente anterior $(t-1)$. Assim, simplificando a equação (1), considerando o retorno excedente da carteira de mercado e do ativo " $i$ " como sendo iguais ao seu valor nominal menos o valor do ativo livre de risco, a equação do CAPM condicional será:

$$
E\left[R_{i t} \mid I_{t-1}\right]=\beta_{i, t-1} R_{m t} \mid I_{t-1}
$$

em que $R_{i t}$ igual ao prêmio de risco do ativo $i ; R_{m t}$ igual ao prêmio de risco da carteira de mercado.

A expectativa não-condicionada do retorno excedente do ativo, como destacam Jagannathan \& Wang (1996), poderá ser representada por: ${ }^{5}$

$$
E\left[R_{i t}\right]=\bar{\beta}_{i} \gamma_{t-1}+\operatorname{Cov}\left(R_{m t-1}, \beta_{i t-1}\right)
$$

$\operatorname{para} \bar{\beta}_{i}=E\left[\beta_{i t-1}\right] \quad \gamma_{t-1}=E\left[R_{m t-1}\right]$

Neste caso, o coeficiente $\gamma_{t-1}$ representa a esperança do prêmio de risco de mercado, tal como no modelo incondicional, sendo que, se a covariância do prêmio de risco de mercado e da série de betas condicionais for zero o modelo condicional tenderá para o modelo incondicional, apresentando uma função linear entre prêmio de risco do ativo e prêmio de risco do mercado. No entanto, conforme destacam Jagannathan \& Wang (1996), em períodos de instabilidade econômica, quando o prêmio de mercado tende a ser maior, as firmas mais alavancadas apresentam maior chance de ter dificuldades financeiras e, portanto, maiores betas. Dessa forma, os betas tendem a ser correlacionados com o prêmio de risco de mercado.

Lewellen \& Nagel (2006) desenvolveram a análise de Jagannathan \& Wang (1996) e encontraram a relação do beta não condicional $\left(\beta_{i}\right)$ com o beta condicional esperado $\left(\bar{\beta}_{i}\right)$. Para isso, consideraram que $\beta_{i, t-1}=\bar{\beta}_{i}+\xi_{i t-1}$, em que $\xi_{i t-1}$ é o componente da variação no tempo, de média zero. Os autores fizeram com que a equação (3) fosse simplificada como uma estimação do CAPM condicional em $R_{i t}=\beta_{i, t-1} R_{m t}+\epsilon_{t}$. Com isso, a covariância incondicionada de $R_{i t}$ com $R_{m t}$ será:

$$
\operatorname{Cov}\left(R_{i t}, R_{m t}\right)=\bar{\beta}_{i} \sigma_{m}^{2}+E\left[\xi_{i t-1} R_{m t}^{2}\right]-E\left[\xi_{i t-1} R_{m t}\right] \cdot E\left[R_{m t}\right]
$$

Considerando que $E\left[R_{m t-1}\right]=\gamma_{t-1}, E\left[\xi_{i t-1}\right]=0, E\left[R_{m t-1}^{2}\right]=\gamma_{t-1}^{2}-$ $\sigma_{m t-1}^{2}$ e $E\left[R_{m t}\right]=\gamma_{t}$, o segundo termo da equação (4) será igual a $C o v$ $\left(\xi_{i t-1}, \gamma_{t-1}^{2}-\sigma_{m t-1}^{2}\right)$ e o último termo, igual a $\gamma_{t} \operatorname{Cov}\left(\xi_{i t-1}, \gamma_{t-1}\right)$ e, fazendo-se

${ }^{5}$ Para uma demonstração detalhada desta equação, ver Jagannathan \& Wang (1996). 
a transformação $\gamma_{t-1}=\gamma_{t}+\left(\gamma_{t-1}-\gamma_{t}\right)$, a equação (4), então, pode então ser reescrita conforme destacado por Lewellen \& Nagel (2006):

$$
\begin{aligned}
\operatorname{Cov}\left(R_{i t}, R_{m t}\right) & =\bar{\beta}_{i} \sigma_{m t}^{2}+\operatorname{Cov}\left(\xi_{i t-1}, \sigma_{m t-1}^{2}\right)+\gamma_{t} \operatorname{Cov}\left(\xi_{i t-1}, \gamma_{t-1}\right) \\
& +\operatorname{Cov}\left[\xi_{i t-1},\left(\gamma_{t-1}-\gamma_{t}\right)^{2}\right]
\end{aligned}
$$

Lembrando que $\beta_{i, t-1}=\bar{\beta}_{i}+\xi_{i t-1}$, pode-se substituir $\xi_{i t-1}$ por $\beta_{i, t-1}$ na equação (5). Dessa forma, o beta não-condicionado pode ser colocado em evidência, e assim, ter-se-á a relação do beta não condicionado com o beta condicionado, considerando que variância e as covariâncias se alteram com o passar do tempo:

$$
\begin{aligned}
\beta_{i t} & =\bar{\beta}_{i}+\frac{\gamma_{t}}{\sigma_{m t}^{2}} \operatorname{Cov}\left(\beta_{i t-1}, \gamma_{t-1}\right)+\frac{1}{\sigma_{m t}^{2}} \operatorname{Cov}\left[\beta_{i t-1},\left(\gamma_{t-1}-\gamma_{t}\right)^{2}\right] \\
& +\frac{1}{\sigma_{m t}^{2}} \operatorname{Cov}\left(\beta_{i t-1}, \sigma_{m t-1}^{2}\right)
\end{aligned}
$$

A expressão (6) indica que o beta não condicional irá se diferenciar da esperança do beta condicional se este apresentar covariância com o prêmio de risco do mercado, com o termo $\left(\gamma_{t-1}-\gamma_{t}\right)^{2}$ ou ainda se apresentar covariância com a volatilidade condicional do mercado (Lewellen \& Nagel, 2006).

Jensen (1969), em um estudo desenvolvido com o intuito de avaliar o retorno de fundos mútuos, apresentou a medida alfa, que informa se a carteira teve retorno superior ao esperado. Assim, para um ganho superior ao de mercado, dimensionando os riscos, o retorno da carteira precisa ser maior do que o retorno econômico esperado pelo CAPM não condicional, o que define a medida de desempenho alfa de Jensen:

$$
\alpha_{i t}=E\left[R_{i t}\right]-\beta_{i t} \gamma_{t}
$$

em que, $\alpha_{i t}=$ alfa de Jensen da carteira $i$ para o momento não condicional; $R_{i t}=$ o retorno excedente da carteira $i ; \beta_{i t}=$ o beta não condicional estimado; $\gamma_{t}=\mathrm{a}$ esperança de retorno excedente do mercado no momento não condicional.

Lewellen \& Nagel (2006) partem da equação (7) para estimar a diferença do alfa incondicional para o alfa condicional, lembrando que se o CAPM é válido, então a existência do alfa para alguma carteira é uma anomalia. Logo, substituindo em (7) a esperança de retorno por (3) tem-se:

$$
\alpha_{i t}=\left(\bar{\beta}_{i}-\beta_{i t}\right) \gamma_{t}+\operatorname{Cov}\left(R_{m t-1}, \beta_{i t-1}\right)
$$

Substituindo $\beta_{i t}$ pelo valor encontrado na equação (6) na equação (8), obtémse a expressão do alfa não condicionado, se o CAPM condicional for válido: 


$$
\begin{aligned}
\alpha_{i t} & =\left[1-\frac{\gamma_{t}^{2}}{\sigma_{m t}^{2}}\right] \operatorname{Cov}\left(\beta_{i t-1}, \gamma_{t-1}\right)-\frac{\gamma_{t}}{\sigma_{m t}^{2}} \operatorname{Cov}\left[\beta_{i t-1},\left(\gamma_{t-1}-\gamma_{t}\right)^{2}\right] \\
& -\frac{\gamma_{t}}{\sigma_{m t}^{2}} \operatorname{Cov}\left(\beta_{i t-1}, \sigma_{m t-1}^{2}\right)
\end{aligned}
$$

A equação (9) indica que se o CAPM condicional for válido, esperam-se variações no CAPM incondicional se o beta apresentar covariância significativa com um dos elementos à direita da equação (9): o prêmio de risco do mercado, o termo $\left(\gamma_{t-1}-\gamma_{t}\right)^{2}$ ou a volatilidade condicional do mercado.

\section{Metodologia}

\section{Tratamento dos dados e amostra}

A formação das carteiras pelo critério momento foi feita segundo metodologia de Jegadeesh \& Titman (1993), reaplicada no Brasil por Mussa et al. (2007). Como no trabalho brasileiro esta foi considerada a estratégia mais eficaz para classificar as ações pelos seus retornos em três meses e mantê-las por seis meses, o mesmo procedimento foi adotado na construção das carteiras neste artigo.

As ações foram então classificadas no mês $t$ conforme seus retornos acumulados nos três meses anteriores a t e separadas em cinco carteiras, cada uma representando um quintil dos ativos disponíveis, sendo que as empresas com menor retorno nestes três meses (perdedoras) foram alocadas no primeiro quintil e em quintis superiores conforme seu retorno passado calculado fosse maior, até a carteira do quinto quintil, que contém os ativos com maior retorno passado. Essas carteiras foram então mantidas por seis meses, quando se fez nova classificação dos ativos. Como o mês de início do período da amostra começa no mês de junho, isso significa que para este artigo as carteiras foram reclassificadas nos meses de junho e dezembro. Para a carteira de junho de 1995, por exemplo, foram utilizados dados de maio, abril e março do mesmo ano.

A construção das carteiras pelo critério book-to-market utiliza metodologia similar à de Fama \& French (1993), Fama \& Frech (1996), de forma que os ativos são ordenados em função da relação entre o seu valor contábil pelo seu valor de mercado. O valor de mercado utilizado foi fornecido pela base de dados Economática, que multiplica o valor de mercado não corrigido por proventos pelo número de ações outstanding. Este número de ações já está compensado por splits e novas emissões. Quando a empresa tem ações ON e PN, é utilizada a multiplicação ponderada entre o número de ações de cada tipo. Quando apenas um tipo de ação possui cotação, é utilizado para o cálculo somente o valor disponível. O valor contábil é medido pelo patrimônio líquido da empresa no fechamento do exercício de cada ano. Foram descartadas as ações com patrimônio líquido negativo. 
Assim como na formação das carteiras de momento, são formadas cinco carteiras book-to-market, cada uma contendo um quintil dos ativos com dados disponíveis. A carteira com menor índice valor contábil sobre valor de mercado é aquela formada pelo primeiro quintil dos dados, e assim por diante. A cada doze meses as carteiras são reformuladas, com base nos dados contábeis do ano anterior e no valor de mercado do mês de formação das carteiras.

De modo similar à construção das carteiras book-to-market, utilizou-se novamente a metodologia de Fama \& French (1993), Fama \& Frech (1996) na modelagem das carteira de efeito tamanho, sendo que também foram desconsiderados ativos com patrimônio líquido negativo e o valor de mercado utilizado é o mesmo já descrito na construção das carteiras book-to-market. Os ativos foram então ordenados por ordem de tamanho no mês de junho de cada ano estudado, e foram divididos em cinco carteiras cada uma contendo um quintil da ordem por valor de mercado. O primeiro quintil contém os ativos menores, e assim por diante até o quinto quintil, que contém os ativos de maior valor de mercado na data de formação das carteiras, no começo de junho de cada ano da amostra.

O presente estudo conduz uma análise do período de junho de 1995 a julho de 2008. Para tanto, foram utilizados dados da Bovespa de janeiro de 1995 a julho de 2008, utilizando a base de dados Economática. A escolha procurou evitar o período antes do Plano Real, por sua instabilidade monetária, e pelo fato de que um número significativo de trabalhos utilizarem este ponto de partida no tempo, o que facilita a comparação de resultados.

Só um papel por empresa negociada na Bovespa foi analisado e, quando a empresa apresentava mais de um papel negociado em bolsa, foi escolhido aquele com maior liquidez, correspondendo então ao papel que apresentou maior número de negociações no período de análise.

Foram desconsiderados os ativos de instituições financeiras pela característica específica destes ativos, que têm alto grau de endividamento financeiro, o que influencia a análise do índice book-to-market e, ainda, pelo fato de que este endividamento não possui o mesmo significado para as empresas não-financeiras.

Ativos que entraram no mercado a partir de 2007 foram desconsiderados por dois motivos: primeiro, como o estudo termina em julho de 2008 sua participação no período seria pequena; e segundo, o número de initial public offerings (IPOs) neste período é muito maior do que o de anos anteriores, sendo de 68 entrantes em 2007 e 2008, enquanto que de 2004 a 2006 foram 42 novos entrantes (BOVESPA, 2010). Casotti \& Motta (2008), estudando IPOs do período de 2004 a 2006, chegaram à conclusão de que os ativos podem estar superavaliados. Miranda \& Amstalden (2009), estudando o período de 2004 ao primeiro semestre de 2008, encontram evidências tanto de subavaliação como de superavaliação de ativos. Assim, a exclusão desses ativos ajuda a evitar tal efeito na amostra. 
Os retornos mensais dos ativos são calculados pela expressão:

$$
R_{t}=\frac{P_{t}}{P_{t-1}}-1
$$

em que $P$ é o preço ajustado por dividendos, desdobramentos e outros proventos. Os valores foram deflacionados pelo índice de preços ao consumidor amplo (IPCA) calculado pelo Instituto Brasileiro de Geografia e Estatística (IBGE) e disponibilizado na base de dados do Economática. Os preços mensais são determinados pela cotação no último dia útil do mês. E, assim como em Mantovanini (2003), adotou-se o seguinte procedimento no caso de ausência de negociações no último dia útil: não havendo cotação disponível no último dia do mês, é adotada a cotação do dia útil anterior e não havendo cotação para este dia, busca-se a cotação do primeiro dia útil do mês subsequente, seguindo-se dessa forma até completar cinco tentativas. Foram também excluídas ações com retornos não contínuos, o que significa que ações que não apresentem retorno mensal para qualquer mês do período na construção das carteiras foram excluídas da análise daquele período. A quantidade de ações utilizada na amostra varia entre 98 ações e 175 ações durante o período escolhido. Outra razão para se escolher ativos de maior liquidez se deve aos resultados de Ribenboim (2002), que aceitou o modelo condicional apenas para as ações mais líquidas.

Como ativo livre de risco utilizou-se a média da taxa diária dos certificados de depósitos interbancários (CDI), descontado o efeito da inflação pelo IPCA. Segundo Famá et al. (2002), tanto a taxa CDI quanto a poupança são boas estimativas para o ativo livre de risco no Brasil. No período estudado a taxa CDI média foi de $1.01 \%$ a.m, descontando o efeito da inflação. Para o ativo de mercado, foi utilizado o Índice Bovespa. No período analisado este índice apresentou uma média de $1,765 \%$ a.m. e um desvio padrão de $9,836 \%$. A correlação do Ibovespa com a taxa CDI é de 0,047 no período

\section{Testes do CAPM}

O modelo CAPM foi estimado por Mínimos Quadrados Ordinários (MQO) das carteiras de tamanho, book-to-market e momento, na forma da equação:

$$
R_{i}-R_{f}=a+b\left(R_{m}-R_{f}\right)+e
$$

em que, $R_{i}$ é o retorno da carteira no período estudado; $R_{f}$ é o retorno do ativo livre de risco no período estudado; $R_{m}$ é o retorno de mercado no período estudado; $a$ é a estimativa do alfa de Jensen; $b$ é a estimativa de $\alpha$; $e$ é o resíduo da estimação de $i$.

Utilizou-se para o prêmio de mercado tanto a diferença do Ibovespa e da taxa CDI como a diferença da carteira de mercado, calculada a partir da amostra, e da taxa CDI. A carteira de mercado neste artigo é especificada pela média ponderada por retorno de toda amostra estudada. 
O teste do modelo condicional neste artigo segue a metodologia proposta por Lewellen \& Nagel (2006), que utiliza MQO para estimar equações do CAPM em curtos períodos de tempo. Os autores utilizam retornos com frequência diária e semanal para estimar o CAPM condicional nos EUA em períodos de três e seis meses; e frequência semanal e mensal para estimação em período de um ano. Para este artigo, foram feitas equações a cada doze meses, utilizando os retornos mensais das carteiras conforme a equação (11) utilizada no teste do CAPM incondicional, tendo em vista que a quantidade de ativos da Bovespa é menor que nas bolsas norte-americanas, restringindo o período de variação condicional dos betas neste artigo, já que não são estudados períodos trimestrais e semestrais. A este respeito, cabe destacar que os resultados de Lewellen e Nagel indicaram que a escolha deste período não influenciou na conclusão do traballho.

\section{Resultados}

\section{Comportamento das carteiras book-to-market, momento e tamanho}

A Tabela 1 mostra que os resultados diferem de outros resultados encontrados na literatura brasileira para carteiras de momento, tais como em Mussa et al. (2007) e Minardi (2004), e que a carteira com melhor retorno passado não é necessariamente a que vai ter melhor retorno futuro. Pode-se notar que a média dos retornos das carteiras, com significância de 5\%, é diferente de zero. Outro ponto a se destacar é o fato de a carteira com melhor retorno passado $\left(5^{\circ}\right.$ quintil $)$ não apresentar a maior média de retorno, independente de como foi calculado o retorno das carteiras. A diferença entre a carteira ganhadora (quinto quintil) e a carteira perdedora (primeiro quintil), é de $0,17 \%$ a.m. Não se pode rejeitar a hipótese desta diferença ser igual a zero pelo teste $t$, diferentemente do calculado por Mussa et al. (2007) de 1,4\% a.m., e estatisticamente significante. Cabe ressaltar que o trabalho supracitado analisa o período de junho de 1995 a julho de 2006 e, ajustando as médias do presente estudo para este mesmo período, os valores aumentam, mas não chegam próximos daquele trabalho, provavelmente pela escolha dos autores por utilizar ativos de instituições financeiras em sua amostra. A estratégia de comprar ganhadores e vender perdedores fica em $0,32 \%$ ao mês para carteiras não ponderadas, mas estes retornos após o teste t continuam não rejeitando a hipótese de serem iguais a zero. Isso pode ter ocorrido pelo fato deste artigo utilizar uma base de dados que não considera empresas do setor financeiro, ao contrário de Mussa et al. (2007). Uma análise complementar pelo índice de Sharpe mostra que o prêmio por unidade de risco das carteiras de momento não apresenta um comportamento claro de que carteiras vencedoras têm um retorno maior que carteiras perdedoras.

O efeito book-to-market na média de retorno das carteiras é evidente, sendo que a carteira do quinto quintil tem retorno estatisticamente maior do que todas as outras carteiras, os resultados são equivalentes aos de Mescolin et al. (1997), Bruni (1998), Ramos et al. (2000), Oliveira \& Carrete (2005), Neves \& Leal (2003), 
Cupertino \& Coelho (2006), Souza (2006) e Mussa et al. (2008). Pelo índice de Sharpe pode-se verificar que quanto maior o quintil maior o retorno por unidade de risco aumenta.

As carteiras do critério tamanho obtiveram resultados que indicam que a carteira do primeiro quintil tem o maior retorno médio no período do que qualquer outra carteira, sendo que este retorno é estaticamente relevante a 5\% de significância, e maior do que o retorno da carteira do quinto quintil. Isso significa que carteiras de empresas menores possuem retorno superior ao de carteiras de empresas maiores na amostra estudada. Esses resultados vão de encontro aos resultados de Bruni (1998) e Bonomo \& Garcia (2002), que encontram um retorno maior nas carteiras de maior tamanho do que nas carteiras de menor tamanho. O resultado está também na mesma linha daqueles obtidos por Costa \& O'hanlon (2000), que estudaram as décadas de 70 e 80 , Bonomo \& Dall'agnol (2003) que pesquisaram o período de 1986 a 2000, e Mantovanini (2003), que encontrou um retorno médio do fator SMB (Small minus Big) ${ }^{6}$ do modelo de Fama \& French (1993) positivo, indicando que empresas menores têm retornos maiores do que empresas maiores. Os estudos no mercado internacional, tais como os de Banz (1981) e de Fama \& French (1992, 1993), Fama \& Frech (1996), encontraram um retorno maior para empresas menores. Também é importante ressaltar que a carteira de empresas menores $\left(1^{\circ}\right.$ quintil) possui o maior valor de índice de Sharpe entre as carteiras formadas pelo critério de tamanho.

Tabela 1

Estatísticas descritivas das carteiras

\begin{tabular}{lcccccc}
\hline Tipo & Quintil & Média & $\begin{array}{c}\text { Desvio } \\
\text { padrão }\end{array}$ & $\begin{array}{c}t \\
\text { estatístico }\end{array}$ & Prob. & $\begin{array}{c}\text { Índice de } \\
\text { Sharpe }\end{array}$ \\
\hline Momento & 1 & 0,0194 & 0,0939 & 2,579 & $1,08 \%$ & 0,0988 \\
Momento & 2 & 0,0209 & 0,0813 & 3,2079 & $0,16 \%$ & 0,1325 \\
Momento & 3 & 0,0211 & 0,0735 & 3,5883 & $0,04 \%$ & 0,1497 \\
Momento & 4 & 0,0287 & 0,1112 & 3,2281 & $0,15 \%$ & 0,1676 \\
Momento & 5 & 0,0211 & 0,0813 & 3,2417 & $0,15 \%$ & 0,1352 \\
\hline book-to-market & 1 & 0,0156 & 0,0868 & 2,2388 & $2,66 \%$ & 0,0628 \\
book-to-market & 2 & 0,0157 & 0,0804 & 2,4379 & $1,59 \%$ & 0,0695 \\
book-to-market & 3 & 0,0178 & 0,0852 & 2,609 & $1,00 \%$ & 0,0902 \\
book-to-market & 4 & 0,0183 & 0,0795 & 2,867 & $0,47 \%$ & 0,1025 \\
book-to-market & 5 & 0,0342 & 0,1277 & 3,3458 & $0,10 \%$ & 0,1887 \\
\hline Tamanho & 1 & 0,0332 & 0,1305 & 3,1781 & $0,18 \%$ & 0,177 \\
Tamanho & 2 & 0,0152 & 0,0784 & 2,429 & $1,63 \%$ & 0,0656 \\
Tamanho & 3 & 0,0199 & 0,0879 & 2,8192 & $0,54 \%$ & 0,1108 \\
Tamanho & 4 & 0,0181 & 0,083 & 2,7277 & $0,71 \%$ & 0,0967 \\
Tamanho & 5 & 0,0151 & 0,0839 & 2,2422 & $2,64 \%$ & 0,059 \\
\hline
\end{tabular}

$T$ estatístico para hipótese da média ser igual a zero.

Fonte: Elaborado pelos autores.

${ }^{6}$ Estimado pela diferença de retorno entre uma carteira com ativos das menores empresas e uma formada com ativos das maiores empresas. Para aprofundar no cálculo ver Fama \& French (1993). 


\section{Teste do CAPM incondicional}

Os resultados do CAPM com o retorno da Ibovespa estão na Tabela 2. Os erros-padrão dos coeficientes foram calculados a partir do Método de Momentos Generalizado (MMG), pois não se pode descartar as hipóteses de presença de heterocedasticidade, autocorrelação e de não-normalidade das equações estimada pelo MQO em todas as carteiras.

Tabela 2

CAPM com retorno de mercado Ibovespa

Teste do modelo CAPM estático pela fórmula $R_{i}-R_{f}=a+b\left(R_{m}-R_{f}\right)+e$, intercepto igual à estimativa de $a$ e beta igual à estimativa de $b$

\begin{tabular}{lcccccc}
\hline Tipo & Quintil & Intercepto & $\begin{array}{c}t \\
\text { estatístico }\end{array}$ & Beta & $\begin{array}{c}t \\
\text { estatístico }\end{array}$ & $\begin{array}{c}\mathrm{R}^{2} \\
\text { ajustado }\end{array}$ \\
\hline Momento & 1 & 0,0035 & 0,5779 & 0,7705 & 14,0404 & 0,5637 \\
Momento & 2 & 0,0055 & 1,1113 & 0,6947 & 16,964 & 0,6083 \\
Momento & 3 & 0,0062 & 1,431 & 0,6415 & 15,1182 & 0,6253 \\
Momento & 4 & 0,0126 & $1,9224^{*}$ & 0,7997 & 7,7467 & 0,4331 \\
Momento & 5 & 0,0055 & 1,1851 & 0,7331 & 21,0405 & 0,6742 \\
\hline book-to-market & 1 & $-0,0002$ & $-0,041$ & 0,7477 & 9,7516 & 0,6237 \\
book-to-market & 2 & 0,0003 & 0,0623 & 0,7056 & 15,3012 & 0,642 \\
book-to-market & 3 & 0,0022 & 0,4398 & 0,726 & 21,2985 & 0,6058 \\
book-to-market & 4 & 0,0032 & 0,6395 & 0,6529 & 13,974 & 0,5541 \\
book-to-market & 5 & 0,0176 & $\mathbf{2 , 1 4 4 4}$ & 0,858 & 7,3985 & 0,377 \\
\hline Tamanho & 1 & 0,0171 & $1,9160 *$ & 0,7899 & 6,0136 & 0,3042 \\
Tamanho & 2 & 0,0007 & 0,138 & 0,5873 & 13,7404 & 0,4615 \\
Tamanho & 3 & 0,0044 & 0,7463 & 0,7096 & 11,3434 & 0,5383 \\
Tamanho & 4 & 0,0024 & 0,5359 & 0,7514 & 14,7571 & 0,6848 \\
Tamanho & 5 & $-0,0015$ & $-0,5399$ & 0,8494 & 26,3712 & 0,8696 \\
\hline
\end{tabular}

Regressões por MQO, $t$-estatístico por MMG.

Valores em negrito significantes a $5 \%$.

* Valores significantes a $10 \%$.

Fonte: Elaborado pelos autores.

Para as carteiras do critério tamanho, a carteira do primeiro quintil apresenta a constante significativa a $10 \%$, indicando a existência de um efeito tamanho, pois o intercepto de dos outros quintis não podem ter a hipótese nula de que são iguais a zero, rejeitadas a um nível de significância de $10 \%$. Isto mostra que o efeito tamanho não explicado pelo CAPM incondicional foi similar a de outros estudos no Brasil como Costa \& O'hanlon (2000) e Bonomo \& Dall'agnol (2003).

A carteira pelo critério de book-to-market do quinto quintil foi a única com intercepto significante a $5 \%$ entre aquelas construídas por este critério. A amostra indica, dessa forma, resultados semelhantes a estudos anteriores, como os de Mussa et al. (2008) e Mantovanini (2003).

Das carteiras do critério momento não se pode afirmar a existência de uma anomalia de momento, uma vez que somente a carteira do $4^{\circ}$ quintil apresentou intercepto estatisticamente positivo a $10 \%$ de significância. 
O R-quadrado ajustado das carteiras com intercepto significante apresenta um valor menor que das outras carteiras, indicando que nestes casos o modelo CAPM além de apresentar um alfa significante, também não apresentou boa explicação dos retornos dos ativos.

\section{Teste do modelo CAPM condicional}

Utilizou-se a estimação por MQO, em regressões com retornos de 12 meses, a partir de julho de um ano até junho do ano seguinte. Deste procedimento resultam 13 estimações para cada uma das 15 carteiras testadas neste artigo. Neste caso, não foi necessário utilizar erros padrão robustos, calculados por MMG, uma vez que os testes de Breusch-Pagan e White não puderam rejeitar a hipótese de homecedasticidade, normalidade e de ausência de autocorrelação dos resíduos em $92 \%$ das regressões analisadas.

Tabela 3

Testes do alfa condicional

Teste do modelo CAPM condicional pela fórmula $R_{i}-R_{f}=a+b\left(R_{m}-R_{f}\right)+e$, em regressões de $12 \mathrm{em} 12$ meses. A média do alfa condicional é igual a $E[a]$ de todas as 13 regressões estimadas. O erro padrão igual ao calculado pela série de 13 alfas estimados e não da média dos erros padrão das regressões

\begin{tabular}{|c|c|c|c|c|c|c|c|}
\hline Tipo & Quintil & Média & $\begin{array}{c}\text { Erro } \\
\text { padrão }\end{array}$ & $\begin{array}{c}t \\
\text { estatístico }\end{array}$ & Prob. & Máx. & Mín. \\
\hline Momento & 1 & 0.0042 & 0.0068 & 0.6110 & 0.5517 & 0.0414 & $\overline{(0.0369)}$ \\
\hline Momento & 2 & 0.0074 & 0.0052 & 14.294 & 0.1765 & 0.0237 & $(0.0456)$ \\
\hline Momento & 3 & 0.0049 & 0.0039 & 12.548 & 0.2316 & 0.0276 & $(0.0271)$ \\
\hline Momento & 4 & 0.0119 & 0.0056 & 21.327 & $0.0526^{*}$ & 0.0428 & $(0.0295)$ \\
\hline Momento & 5 & 0.0036 & 0.0046 & 0.7859 & 0.4460 & 0.0228 & $(0.0259)$ \\
\hline book-to-market & 1 & 0.0002 & 0.0062 & 0.0291 & 0.9772 & 0.0395 & $\overline{(0.0343)}$ \\
\hline book-to-market & 2 & 0.0007 & 0.0045 & 0.1559 & 0.8785 & 0.0202 & $(0.0279)$ \\
\hline book-to-market & 3 & 0.0017 & 0.0058 & 0.2903 & 0.7762 & 0.0280 & $(0.0535)$ \\
\hline book-to-market & 4 & 0.0013 & 0.0056 & 0.2304 & 0.8214 & 0.0337 & $(0.0401)$ \\
\hline book-to-market & 5 & 0.0174 & 0.0083 & 20.951 & $0.0563^{*}$ & 0.0747 & $(0.0512)$ \\
\hline Tamanho & 1 & 0.0156 & 0.0090 & 17.308 & 0.1071 & 0.0769 & $(0.0569)$ \\
\hline Tamanho & 2 & 0.0004 & 0.0058 & 0.0697 & 0.9455 & 0.0300 & $(0.0309)$ \\
\hline Tamanho & 3 & 0.0026 & 0.0068 & 0.3798 & 0.7103 & 0.0319 & $(0.0552)$ \\
\hline Tamanho & 4 & 0.0033 & 0.0047 & 0.6905 & 0.5021 & 0.0286 & $(0.0256)$ \\
\hline Tamanho & 5 & $(0.0005)$ & 0.0023 & $(0.2213)$ & 0.8283 & 0.0125 & $(0.0181)$ \\
\hline
\end{tabular}

Valores em negrito significantes a $5 \%$.

*Valores significantes a $10 \%$.

Fonte: Elaborado pelos autores.

Os resultados da média e da estatística $t$ dos interceptos estimados pelo modelo condicional encontram-se na Tabela 3. Em comparação com os dados do CAPM incondicional, apenas 2 carteiras apresentaram intercepto significativo a $10 \%$ no CAPM condicional, contra 3 do CAPM incondicional. No entanto, esse número deve ser visto com cautela, uma vez que a amostra de alfas de Jensen condicionais tem um tamanho de 13, enquanto que a estimação do CAPM incondicional foi feita com 156 observações. Logo, as estatísticas do CAPM condicional são mais 
penalizadas, por terem menor número de graus de liberdade. Os interceptos significativos estimados foram os mesmos do CAPM incondicional, com exceção da carteira de tamanho do $1^{\circ}$ quintil que é significativo não a $10 \%$, mas a $10,71 \%$.

É preciso destacar que os alfas variam bastante no tempo, sendo que o seu valor mínimo em todas as carteiras é negativo. Verificando as regressões uma a uma, revelou-se que a frequência de alfas negativos foi maior no período de julho de 1995 a junho de 1999, voltando a ser alta entre julho de 2007 a junho de 2008. A quebra estrutural identificada por Teixeira \& Zerbini (2001) pode ser parte da explicação na mudança de comportamento dos alfas após a regressão de julho de 1998 a junho de 1999.

Com os resultados da Tabela 3 já se pode dizer que, em termos de interceptos, o modelo condicional pouco melhora em relação ao modelo incondicional. Todavia, a estimação do modelo condicional mostra que os interceptos tendem a variar de acordo com o tempo.

Para verificar se há variação nos betas condicionais, calculou-se a variância dos betas estimados pela média do erro padrão apresentada nas regressões de 12 meses, pelo desvio padrão das séries de betas estimados e pelo desvio padrão implícito dos betas verdadeiros. Lewellen \& Nagel (2006) estimam a forma de calcular o desvio padrão dos betas verdadeiros implícitos considerando que $b_{t}=\beta_{t}+e_{t}$, assim o beta condicional estimado é igual ao beta condicional verdadeiro mais o erro da amostra. Se $b_{t}$ é um estimador não-viesado de $\beta_{t}$, implicando que $\beta_{t}$ e $e_{t}$ não apresentam correlação, a variância de $b_{t}$ é igual a soma das variâncias de $\hat{a}_{t}$ e $e_{t}$. Dessa forma, o desvio padrão implícito de $\beta_{t}$ é igual a $\sqrt{\operatorname{var}\left(b_{t}\right)-\operatorname{var}\left(e_{t}\right)}$. A variável $\operatorname{var}\left(e_{t}\right)$ é estimada pela média das variâncias das equações de 12 meses. O desvio padrão implícito busca melhorar a estimativa de variância dos betas, pois, como lembram Lewellen \& Nagel (2006), parte da variância dos betas estimados pode ser devida a erro de amostragem.

Os resultados da Tabela 4 mostram que os betas estimados variam bastante durante o tempo, mesmo controlando pela variância nos erros. Esses resultados são próximos dos encontrados por Lewellen \& Nagel (2006), que obtiveram um desvio padrão implícito dos betas verdadeiros de 0,04 a 0,52 nas suas carteiras com o cálculo dos betas para 12 meses. No presente artigo, este desvio padrão ficou entre 0,10 e 0,26. 
Tabela 4

Betas condicionais

Teste do modelo CAPM condicional pela fórmula $R_{i}-R_{f}=a+b\left(R_{m}-R_{f}\right)+e$, em regressões de 12 em 12 meses. A média do alfa condicional é igual a $E[b]$ de todas as 13 regressões estimadas. O erro padrão igual ao calculado pela série de 13 alfas estimados e não da média dos erros padrão das regressões. O desvio padrão implícito é $\sqrt{\operatorname{var}\left(b_{t}\right)-\operatorname{var}\left(e_{t}\right)}$

\begin{tabular}{lccccccc}
\hline & \multicolumn{1}{c}{ Beta } & Erro padrão & Desvio & Desvio padrão & & \\
Tipo & Quintil & médio & Médio & padrão & implícito & Máx. & Mín. \\
\hline Momento & 1 & 0,7998 & 0,0168 & 0,2605 & 0,2543 & 1,3831 & 0,2925 \\
Momento & 2 & 0,6727 & 0,0148 & 0,1673 & 0,1603 & 0,9277 & 0,3557 \\
Momento & 3 & 0,6898 & 0,0127 & 0,1417 & 0,135 & 0,8941 & 0,3211 \\
Momento & 4 & 0,7954 & 0,0179 & 0,2368 & 0,2222 & 1,1795 & 0,3756 \\
Momento & 5 & 0,7908 & 0,0132 & 0,2023 & 0,1976 & 1,3357 & 0,4649 \\
\hline book-to-market & 1 & 0,7463 & 0,0133 & 0,2641 & 0,2603 & 1,275 & 0,3622 \\
book-to-market & 2 & 0,7426 & 0,0125 & 0,1864 & 0,1809 & 1,112 & 0,4638 \\
book-to-market & 3 & 0,7666 & 0,0149 & 0,1144 & 0,1023 & 0,9933 & 0,6411 \\
book-to-market & 4 & 0,704 & 0,0147 & 0,1712 & 0,1635 & 1,1132 & 0,4084 \\
book-to-market & 5 & 0,8444 & 0,0234 & 0,2716 & 0,2533 & 1,6476 & 0,5582 \\
\hline Tamanho & 1 & 0,7926 & 0,0264 & 0,2262 & 0,199 & 1,371 & 0,5231 \\
Tamanho & 2 & 0,6331 & 0,0166 & 0,1221 & 0,1086 & 0,8765 & 0,3924 \\
Tamanho & 3 & 0,791 & 0,0155 & 0,1839 & 0,1755 & 1,116 & 0,5492 \\
Tamanho & 4 & 0,7642 & 0,0118 & 0,1628 & 0,1572 & 1,0176 & 0,4088 \\
Tamanho & 5 & 0,8202 & 0,0082 & 0,154 & 0,1516 & 1,0525 & 0,5936 \\
\hline
\end{tabular}

Fonte: Elaborado pelos autores.

Confirmando que existe variância nos betas condicionais, resta verificar se a diferença entre o alfa do modelo incondicional pode ser explicado pela equação (9), apresentada no referencial teórico. No entanto, alguns termos podem ser simplificados: o termo $\gamma_{t}^{2} / \sigma_{m t}^{2}$, se calculado pelo prêmio de mercado entre Ibovespa e a taxa CDI é de 0.0067; e o termo $\left(\gamma_{t-1}-\gamma_{t}\right)^{2}$ é bastante pequeno para que seja significativo na análise, e assim sua covariância com o beta condicional, termo da equação (9) apresenta uma média de -0,0000003 entre as carteiras testadas. Assim, a equação (9) pode ser simplificada para:

$$
\alpha_{i t}=\operatorname{Cov}\left(\beta_{i t-1}, \gamma_{t-1}\right)-\frac{\gamma_{t}}{\sigma_{m t}^{2}} \operatorname{Cov}\left(\beta_{i t-1}, \sigma_{m t-1}^{2}\right)
$$

A Tabela 5 mostra o alfa para o modelo incondicional, calculado pela equação (12), e o compara com o alfa das regressões por MQO para o modelo incondicional. Se o modelo condicional fosse válido para explicar os retornos do alfa de Jensen não explicados pelo modelo CAPM incondicional, os valores do estimado pela equação (12) e o estimado pelas equações MQO do modelo incondicional seriam iguais. 
Tabela 5

Estimação do alfa incondicional a partir do modelo condicional

\begin{tabular}{lcccccc}
\hline \multicolumn{1}{c}{ Tipo } & Quintil & $\begin{array}{c}\text { Covar } \\
\left(b_{t}, R_{m t}\right)\end{array}$ & $R_{m t} / S_{m}^{2}$ & $\begin{array}{c}\text { Covar } \\
\left(b_{t}, s_{t}^{2}\right)\end{array}$ & $\begin{array}{c}\text { Alfa estimado } \\
\text { pela equação (12) }\end{array}$ & $\begin{array}{c}\text { Alfa estimado pelo } \\
\text { MQO incondicional }\end{array}$ \\
\hline Momento & 1 & $-0,0009$ & 0,8878 & $-0,0003$ & $-0,0007$ & 0,0035 \\
Momento & 2 & $-0,0017$ & 0,8878 & 0,0002 & $-0,0019$ & 0,0055 \\
Momento & 3 & 0,0008 & 0,8878 & $-0,0005$ & 0,0013 & 0,0062 \\
Momento & 4 & 0,0007 & 0,8878 & 0,0001 & 0,0006 & $0,0126^{*}$ \\
Momento & 5 & 0,0014 & 0,8878 & $-0,0006$ & 0,0019 & 0,0055 \\
\hline book-to-market & 1 & $-0,0004$ & 0,8878 & 0 & $-0,0003$ & $-0,0002$ \\
book-to-market & 2 & $-0,0007$ & 0,8878 & $-0,0003$ & $-0,0005$ & 0,0003 \\
book-to-market & 3 & 0,0002 & 0,8878 & $-0,0003$ & 0,0005 & 0,0022 \\
book-to-market & 4 & 0,0015 & 0,8878 & $-0,0004$ & 0,0019 & 0,0032 \\
book-to-market & 5 & 0,0003 & 0,8878 & 0,0002 & 0,0002 & $\mathbf{0 , 0 1 7 6}$ \\
\hline Tamanho & 1 & 0,0015 & 0,8878 & 0 & 0,0015 & $0,0171^{*}$ \\
Tamanho & 2 & 0 & 0,8878 & $-0,0004$ & 0,0003 & 0,0007 \\
Tamanho & 3 & 0,0012 & 0,8878 & $-0,0006$ & 0,0018 & 0,0044 \\
Tamanho & 4 & $-0,001$ & 0,8878 & 0 & $-0,001$ & 0,0024 \\
Tamanho & 5 & $-0,0007$ & 0,8878 & 0,0003 & $-0,001$ & $-0,0015$ \\
\hline Vam
\end{tabular}

Valores em negrito significantes a $5 \%$.

*Valores significantes a $10 \%$.

Fonte: Elaborado pelos autores.

No entanto, pode-se notar com base na Tabela 5, que os valores do alfa estimado são muito menores do que os do método de MQO no modelo incondicional. Este resultado é semelhante ao encontrado por Lewellen \& Nagel (2006). Para que o CAPM condicional fosse válido, a covariância entre o beta condicional e o prêmio de mercado teria que ser muito maior.

Comparando os resultados do CAPM condicional com outros trabalhos no mercado brasileiro, percebe-se que os resultados aqui encontrados são parecidos com a conclusão de Antunes et al. (2006), pois estes autores não encontraram interceptos significativos para carteiras baseadas no critério tamanho, quando utilizam o CAPM condicional, apesar da significância do alfa condicional neste artigo estar próxima de $10 \%$ para a carteira com empresas menores.

Já os resultados do CAPM condicional corroboram aqueles obtidos por Tambosi (2003), que utiliza o spread entre a taxa DI e a taxa Selic como proxy de informação e testa 35 ativos para o mercado brasileiro. Suas conclusões não indicaram ganho específico no uso desta proxy. A esse respeito, cabe destacar ainda os resultados recentes obtidos por Tambosi et al. (2010), que sinalizam para a importância da incorporação de variáveis relacionadas à variação no ciclo de negócios e ao retorno no capital humano como relevantes para a explicação das variações cross-section dos retornos no mercado brasileiro. Já Barclay et al. (2010) propõem a utilização de modelos condicionais com fatores relacionados à taxa de câmbio para a explicação das variações cross-section dos retornos em mercados emergentes. Outro estudo recente, de Iqbal et al. (2010) discute a aplicabilidade da incorporação de fatores de risco global em mercados emergentes, aspecto que pode ser considerado em estudos analisando o mercado brasileiro. 
Assim, pesquisas que incorporem estes aspectos à abordagem utilizada no presente artigo podem contribuir para o debate da aplicabilidade de modelos condicionais a mercados emergentes.

\section{Conclusões}

Assim como no trabalho de Lewellen \& Nagel (2006) para o mercado norteamericano, o cálculo do CAPM condicional utilizando uma série de regressões de curto prazo apresentou um ganho ínfimo em relação aos alfas de Jensen calculados pelo CAPM incondicional. Todavia, cabe destacar uma limitação deste artigo frente ao estudo norte-americano, o qual está relacionado ao fato do período de tempo utilizado para análise ter sido menor no presente artigo, reduzindo a significância estatística das conclusões do modelo condicional, limitação esta relacionada ao curto período de estabilidade monetária da economia brasileira.

No entanto, ainda assim foi possível verificar que os betas calculados pelo CAPM condicional variam com o tempo, mas não o suficiente para que os alfas do modelo incondicional fossem explicados pelo modelo condicional. Estes resultados indicam que variáveis proxy de informação para modelos condicionais estudados por Jagannathan \& Wang (1996) podem estar capturando mais informações de fatores de risco do que somente a variação dos betas, e assim os mesmos não estão testando o CAPM na forma condicional e sim modelos multi-fatoriais, tal como aponta Cochrane (2005). Assim, a crítica de Jagannathan \& Wang (1996) - de que se o modelo CAPM fosse testado na forma condicional isto seria o suficiente para explicar as anomalias apresentadas na literatura - não pôde ser aceita na amostra estudada neste artigo. Apesar de os betas condicionais não apresentarem a variação necessária para explicar os interceptos das regressões feitas no CAPM incondicional, a evidência de variação dos betas no tempo significa que análises baseadas no CAPM devem ser cautelosas ao utilizarem modelos incondicionais. Esta variação implica que a escolha do tamanho da série temporal para cálculo dos betas pode influenciar a alocação de ativos em carteiras pelos investidores, principalmente quando utilizam estratégias de curto prazo. Trabalhos futuros podem testar a diferença de retorno em carteiras balanceadas através de betas condicionais em relação ao retorno de carteiras balanceadas a partir de betas incondicionais.

Recomenda-se ainda que em estudos posteriores sejam analisadas outras anomalias, que apresentam retornos não explicados pelo CAPM incondicional na literatura, em função do modelo condicional, uma vez que a variação nos betas é verificável. Como sugestão, pode-se investigar o papel da volatilidade estocástica do mercado na explicação das variações cross-section dos retornos, tal como proposto por Ang et al. (2006). Recomenda-se também que a relação book-to-market seja estudada utilizando períodos trimestrais para reavaliação das carteiras, utilizando dessa forma a informação mais recente disponível no mercado. Acreditase ainda que o uso de dados semanais também pode gerar resultados interessantes em estudos posteriores do CAPM condicional, bem como o estudo da variância dos betas condicionais em função de séries normalmente utilizadas como proxy 
de informação na literatura, como a diferença entre spreads de taxas de títulos privados e governamentais.

\section{Referências}

Ang, Andrew, Hodrick, Robert J., Xing, Yuhang, \& Zhang, Xiaoyan. 2006. The Cross-Section of Volatility and Expected Returns. The Journal of Finance, 61, 259-299.

Antunes, Gustavo A., Lamounier, Wagner M., \& Bressan, Aureliano A. 2006. Análise Do Efeito Tamanho Nos Retornos Das Ações de Empresas Listadas Na BOVESPA. Revista de contabilidade \& finanças, 40, 1-16.

Banz, Rolf W. 1981. The Relationship Between Return and Market Value of Common Stocks. Journal of Financial Economics, 9, 3-18.

Barclay, Richard, Fletcher, Jonathan, \& Marshall, Andrew. 2010. Pricing Emerging Market Stock Returns: An Update. Emerging Markets Review, 11, 49-61.

Bonomo, Marco, \& Dall'agnol, Ivana. 2003. Retornos Anormais e Estratégias Contrárias. Revista Brasileira de Finanças, 1, 165-215.

Bonomo, Marco, \& Garcia, Ricardo. 2002. Estimando e Testando O CAPM Condicional Com Efeitos ARCH Para O Mercado Acionário Brasileiro. Pages 41-52 of: Bonomo, Marco (ed), Finanças Aplicadas Ao Brasil. São Paulo: FGV editora.

BOVESPA. 2010. Empresas - IPOs Recentes. Disponível em: http://www.bmfbovespa.com.br/cias-listadas/consultas/ ipos-recentes/ipos-recentes.aspx?Idioma=pt-br. Acesso em: 24 abr. 2010.

Bruni, Adriano L. 1998. Uma Análise Do Modelo de Precificação de Ativos Financeiros Na Avaliação de Ações Negociadas Na Bovespa (1988-1996). USP, São Paulo. Dissertação Mestrado. 163p.

Casotti, Felipe P., \& Motta, Luiz J. 2008. Oferta Pública Inicial No Brasil (20042006): Uma Abordagem Da Avaliação Através de Múltiplos e Do Custo de Capital Próprio. Revista Brasileira de Finanças, 6, 157-204.

Cochrane, John H. 2005. Asset Pricing. Revised edn. Princeton and Oxford: Princeton University Press.

Costa, Newton Carneiro A, Jr., \& O'hanlon, John. 2000. O Efeito Tamanho versus O Efeito Mês-Do-Ano No Mercado de Capitais Brasileiro: Uma Análise Empírica. Pages 152-167 of: Costa, N. A., Jr., Leal, R. P., \& Lemgruber, E. F. (eds), Mercado de Capitais - Análise Empírica No Brasil. São Paulo: Atlas. 
Cupertino, César M., \& Coelho, Reinaldo A. 2006. Alavancagem, Liquidez, Tamanho, Risco Imobilizado e Intangíveis e Seu Impacto Sobre O book-tomarket de Empresas Brasileiras. Anais do $6^{\circ}$ Encontro Brasileiro de Finanças. Vitória: SBFIN.

Fama, Eugene F., \& Frech, Kenneth R. 1996. Multifactor Explanation of Asset Pricing Anomalies. Journal of Finance, 56, 55-84.

Fama, Eugene F., \& French, Kenneth R. 1992. The Cross-Section of Expected Stock Returns. Journal of Finance, 47, 427-465.

Fama, Eugene F., \& French, Kenneth R. 1993. Common Risk Factors in the Returns on Stocks and Bonds. Journal of Financial Economics, 33, 3-56.

Famá, Rubens, Barros, Lucas A., \& Silveira, Héber P. 2002. Conceito de Taxa Livre de Risco e Sua Aplicação No Capital Asset Pricing Model - Um Estudo Exploratório Para $O$ Mercado Brasileiro. Anais do $2^{\circ}$ Encontro Brasileiro de Finanças, Rio de Janeiro.

Iqbal, Javed, Brooks, Robert, \& Galagedera, Don A. 2010. Testing Conditional Asset Pricing Models: An Emerging Market Perspective. Journal of International Money and Finance, 29, 897-918.

Jagannathan, Ravi, \& Wang, Zhenyu. 1996. The Conditional CAPM and the Cross-Section of Expected Returns. Journal of Finance, 51, 3-53.

Jegadeesh, Narasimhan, \& Titman, Sheridan. 1993. Returns to Buying Winners and Selling Losers: Implications for Stock Market Efficiency. Journal of Finance, 48, 65-91.

Jensen, Micheal C. 1969. Risk, the Pricing of Capital Assets, and the Evaluation of Investment Portfolios. Journal of Business, 42, 167-247.

Lettau, Martin, \& Ludvigson, Sydney. 2001. Resurrecting the (C)CAPM: A CrossSectional Test When Risk Premia are Time Varying. Journal of Political Economy, 109, 1238-1287.

Lewellen, Jonathan, \& Nagel, Stephan. 2006. The Conditional CAPM Does Not Explain Asset-Pricing Anomalies. Journal of Financial Economics, 82, 289314.

Lintner, John. 1965. The Valuation of Risk Assets and the Selection of Risk Investments in Stock Portfolio and Capital Budgets. Review of Economics and Statistics, 47, 13-37.

Mantovanini, Rosaura M. 2003. A Relação Risco-Retorno: Análise Do Desempenho de Modelos de Risco e de Um Modelo Comportamental No Mercado Brasileiro. FGV/EAESP, São Paulo. Tese de Doutorado. 
Mayers, David. 1972. Non Marketable Assets and Capital Market Equilibrium under Uncertainty. Pages 223-248 of: Jensen, M. C. (ed), Studies in the Theory of Capital Markets. New York: Praeger Publishers.

Mescolin, Alexandre, Braga, Cláudio M., \& Costa, Newton Carneiro A., Jr. 1997. Risco e Retorno Das Value e Growth Stocks No Mercado de Capitais Brasileiro. Anais do XXI ENANPAD. Rio de Janeiro: ANPAD.

Minardi, Andrea. 2004. Retornos Passados Prevêem Retornos Futuros? Rae-eletrônica, 3, 1-18. Disponível em: http://www.rae.com.br/ eletronica/index. cfm?FuseAction=Artigo\&ID=1738\&Secao=FINAN $\backslash$ cCAS2\&Volume $=3 \&$ Numero $=2 \& A n o=2004$. Acesso em: 20 jan. 2007.

Miranda, Felipe, \& Amstalden, Rodolfo C. 2009. Estreantes Nascem Gauche: Avaliando a Hipótese de Underpricing Em IPOs No Brasil. Pages 44-52 of: Gala, Paulo, \& Rochman, Ricardo (eds), Caderno de Pesquisas: Investimentos. São Paulo: FGV-EESP. Disponível em: http://www.eesp.fgv.br/ _upload/publicacao/498ae2fe24a49.pdf\#page=45. Acesso em: $30 \mathrm{de}$ maio de 2009.

Mossin, Jan. 1966. Equilibrium in a Capital Asset Market. Econometrica, 34, $768-783$.

Mussa, Adriano, Trovao, Ricardo, Santos, José O., \& Famá, Rubens. 2007. A Estratégia de Momento de Jegadeesh e Titman e Suas Implicações Para a Hipótese de Eficiência Do Mercado Acionário Brasileiro. Anais do X SEMEAD, São Paulo: FEA-USP.

Mussa, Adriano, Securato, José R., Santos, José O., \& Famá, Rubens. 2008. A Influência Das Condições Do Mercado Acionário e Da Política Monetária No Comportamento Dos Indicadores de Risco Tamanho, Índice Book-to-Market e Momento, No Mercado Acionário Brasileiro. Anais do VII Encontro da Sociedade Brasileira de Finanças, Rio de Janeiro: SBFIN.

Neves, Myrian B., \& Leal, Ricardo P. C. 2003. Anomalias No Mercado de Ações e O Crescimento Do PIB Brasileiro. Anais do 30 Encontro Brasileiro de Finanças. São Paulo: Sociedade Brasileira de Finanças.

Oliveira, Raquel F., \& Carrete, Liliam S. 2005. Estudo Empírico Sobre a Previsibilidade Do Retorno de Mercado No Brasil. Anais do $5^{\circ}$ Encontro Brasileiro de Finanças. São Paulo: Sociedade Brasileira de Finanças.

Ramos, Patrícia R., Picanço, Marcelo B., \& Costa, Newton A., Jr. 2000. Retornos e Riscos Das value e growth stocks No Mercado Brasileiro. Pages 124-138 of: Costa, N. C. A., Jr., Leal, R. P. C., \& Lemgruber, E. F. (eds), Mercado de Capitais - Análise Empírica No Brasil. São Paulo: Atlas. 
Ribenboim, Guilherme. 2002. Testes de Versões Do Modelo CAPM No Brasil. Pages 18-40 of: Bonomo, M. (ed), Finanças Aplicadas Ao Brasil. São Paulo: FGV editora.

Roll, Richard. 1977. A Critique of the Asset Pricing Theory's Tests Part I: On Past and Potential Testability of the Theory. Journal of Financial Economics, 4, $129-177$

Rostagno, Luciano, Soares, Karina C., \& Soares, Rodrigo O. 2006. Estratégias de Valor e de Crescimento Em Ações Na Bovespa: Uma Análise de Sete Indicadores Relacionados Ao Risco. Revista de Contabiliade e Finanças, 42, 7-21.

Sharpe, William F. 1964. Capital Asset Prices: A Theory of Market Equilibrium under Conditions of Risk. Journal of Finance, 19, 425-442.

Souza, Thiago O. 2006. Asset Allocation e Previsibilidade de Retorno Do Ibovespa. Pages 1-16 of: de Finanças, Encontro Brasileiro (ed), Anais Do XI Encontro Brasileiro de Finanças. São Paulo: SBFIN.

Tambosi, Elmo, Filho. 2003. Testando Empiricamente O CAPM Condicional Dos Retornos Esperados De Portfólios Do Mercado Brasileiro, Argentino e Chileno. Universidade Federal de Santa Catarina, Florianópolis. Tese de Doutorado.

Tambosi, Elmo, Filho, Garcia, Fábio G., Imoniana, Joshua O., \& Moreiras, Luiz F. 2010. Teste Do CAPM Condicional Dos Retornos de Carteiras Dos Mercados Brasileiro, Argentino e Chileno, Comparando-Os Com O Mercado NorteAmericano. RAE-Revista de Administração de Empresas, 50.

Teixeira, Nilson, \& Zerbini, Maria B. 2001. Mudanças Estruturais No Mercado Financeiro: A Ótica Do Mercado de Ações. Anais do I Encontro Brasileiro de Finanças. São Paulo: SBFIN. 